\title{
Management of medical care, a fundamental tool for resident doctors
}

\author{
Gestión de la atención médica, herramienta fundamental para los médicos residentes \\ Guillermo Fajardo-Ortiz ${ }^{*}$ and Héctor Robledo² \\ ${ }^{1}$ Faculty of Medicine, Universidad Nacional Autónoma de México; ' 2 nstituto de Oftalmología Conde de la Valenciana. Mexico City. Mexico
}

\begin{abstract}
In the area of medical education, and particularly in our country, medical residencies are the best educational programs for a graduated physicians; however, when young medical doctors begin a residence at hospitals, they hardly possess knowledge about the way medical services work as well as the processes they involve, which directly affects the fulfillment of their tasks, their process of learning and more importantly, it interferes in the services provided by the hospital. Therefore, it is imperative to immerse residents in the management of medical care and let them know that its main function is to harmoniously articulate every medical-administrative process related to patients as well as human, material and financial resources. One of the main goals is to achieve the fulfillment of the hospital's mission and vision with operational efficiency and humanism. This path will help physicians to make the best decisions, as well as achieving an adequate management of resources always remembering that quality in medical services and patient's safety are important.
\end{abstract}

KEY WORDS: Management. Resident physicians. Process. Medical residencies. Competitions.

\section{Resumen}

En el área de la enseñanza médica, y particularmente dentro de nuestro país, las residencias médicas en hospitales son el mejor modelo para realizar un posgrado; sin embargo, cuando un médico joven inicia su residencia y arriba a un hospital, difícilmente posee los conocimientos de los servicios, tipo de pacientes y procesos que se realizan en dicho lugar, lo que repercute directamente en el cumplimiento de sus tareas, aprendizaje y, más importante, los servicios que ofrece el hospital. Por lo tanto, es imperante hacer partícipes a los médicos residentes en la gestión de la atención médica, darles a conocer que esta es la encargada de articular de forma armónica todos los procesos médico-administrativos en los que participan pacientes, recursos humanos, materiales y financieros, para alcanzar el cumplimiento de la misión y la visión hospitalaria con eficiencia operativa y sentido humano. De esta manera será posible orientarlos a realizar una correcta toma de decisiones y una gestión adecuada de los recursos, y a que su contribución en los procesos médico-administrativos brinde un servicio de calidad y seguridad para el paciente.

PALABRAS CLAVE: Gerencia. Médico residente. Procesos. Residencias médicas. Competencias.

\author{
Correspondence: \\ *Guillermo Fajardo-Ortiz \\ Fac. Medicina, UNAM \\ Ciudad Universitaria \\ C.P. 04510, Ciudad de México, México \\ E-mail: gfortiz@unam.mx
}

Date of reception: 06-12-2017

Date of acceptance: 27-01-2018

DOI: 10.24875/CIRUE.M18000010
Cir Cir. 2018;86:65-72

Contents available at PubMed www.cirugiaycirujanos.com 


\section{Introduction}

The issue begins with a question: why is it necessary for resident doctors to have knowledge about medical care management? There is no doubt that people of the clinical environment and other health professionals are unaware of its advantages or consider it unnecessary, but understanding the functioning of this instrument helps to generate an effective, efficient and quality service. Resident doctors are a cornerstone in medical care, as they are in close contact with patients and their institution, and know their problems. In the performance of their clinical and teaching activities, they implicitly practice management activities, particularly in terms of medical-administrative processes, and must make correct and timely decisions. By promoting a management culture in resident physicians, optimizing the use of resources is attempted, in order to obtain better results in medical care, especially in hospitals.

\section{Hospital management}

The hospital is the traditional and optimal medical care establishment for making the medical residency; however, for many administration scholars, it is the most complex organization for several reasons. One of them is the diversity of patients it serves, people for whom medical care exists, and this diversity answers to different situations: health-disease problems, age, gender, socioeconomic status and culture. The second reason is that it has very heterogeneous human capital regarding academic and technical training, experience, age, working hours, gender, wages or salaries, and behaviors and ideas. And a third reason refers to the material and technological resources of medical care, with a variety in equipment, furniture and instruments, size, cost, durability, maintenance and location being found, in such a way that there are from small pieces, such as a pencil, a scalpel or a computer can be, to large ones such as the property, and there are expensive ones, such as a computerized axial tomography and cheap ones, such as a sheet of paper. In other words, in the hospital, there are great disparities; management involves a set of human, social, scientific, technological, economic and political components of diverse cultural and tradition aspects, interlinked in a transdisciplinary and systemic form, and with shared values. Management must harmoniously articulate all medical-administrative processes patients and human, material and financial resources participate in, guiding them towards the achievement of the hospital mission and vision with operational efficiency and human sense. The hospital mission refers to achieving the objectives of the institution with efficacy, ethics and quality; i.e., the mission is the reason for the establishment's existence. On the other hand, the vision is the way in which the hospital is visualized in a particular future, it is a prospective. These attributes are the basis for guaranteeing governance and management excellence, which implies professionalization, de-bureaucratization, expenditure control, productivity, competitiveness, profitability, cost-benefit indicators, strategic planning, application of competences, evaluation of results and technological innovations; all these activities and others more oriented to patient well-being.

\section{Levels of hospital management}

Hospital management comprises three levels according to the hierarchical level it is practiced in:

- Macro-management: it refers to institutional policy, to the decisions of higher authorities, directors, sub-directors or managers, which are delimited by current regulations. Macro-management coordinates general activities, and is oriented to giving an optimal use to all resources, including time and long-term planning; it has global knowledge of departments and services' processes; it affects both other levels, and has extra-institutional projection. This level of management is linked and aligned, when this is the case, with sectoral or government policies and guidelines.

- Meso-management: it is identified with activities of middle management authorities, unit heads, and service and department coordinators, such as reception, admission, quality and patient safety, outpatient clinics, social work, customer service (to the user), public relations, intensive care, auxiliary diagnostic studies and treatment, human resources (talent), nursing, maintenance, biomedical engineering, accounting and finance, information technology and communications, internal auditing, etc. It determines intra-institutional processes.

- Micro-management or clinical management: it refers to actions carried out by medical personnel (including residents), paramedics and technicians, basically related to patients, i.e., of 
medical-administrative processes. Micromanagement is highly important, because it is there where patient life can be jeopardized, either due to the lack of control or implementation of the best practices at each department, for not appropriately following the processes or for lack of supervision by the hierarchical responsible parties in the structure.

Articulation between hierarchical levels can be vertical, horizontal, zigzagging and virtual. Vertical articulation is oriented from senior management posts to the bases, or vice versa; horizontal articulation refers to the linking of activities of the same level; zigzagging articulation relates different levels of hierarchical order; and virtual articulation is digital and manifests itself quickly at all levels.

\section{Medical-administrative processes in clinical management}

Medical-administrative processes in clinical management refer to the conjunction of resources to meet institutional and patient needs and demands in a complementary and logical way. According to the general theory of systems, these processes transform entering components (inputs) into results (outputs), contributing with added or extra values for patients and organization. Inputs refer to all resources: personnel (academic training, technical training, attitude, ideas, experience, talent, problem solving skills, treatment, interest, motivation, dedication to service, willingness to work as a team, etc.), current regulations, resources and financial commitments, technological equipment for diagnosis and medical treatment, facilities, methods, time, etc. Outputs are the products: patient discharges, final costs, resources used, consumed time, etc. The purpose of processes is to offer an adequate service that meets the needs and satisfies the expectations of all stakeholders in quality, safety, efficacy and efficiency aspects; for this to be achieved, it is necessary for those who practice management to have four parallel qualities:

- Responsibility for their own work.

- Commitment to patients, staff, institution and community.

- Initiative and decision-making capacity.

- Acceptance of challenges and, given the case, presentation of proposals for change.

To carry out micromanagement processes it is necessary for resident doctors to have knowledge regarding:
- Accuracy and definition of the processes at different departments and situations: admission, outpatient services, reference-counter-reference, preparation of documents, etc., taking into account that the processes are multifactorial. It is very important for the resident to participate in the processes in an informed manner, observing the regulations on the subject, as described in the General Public Health Council guidelines, in order to act in consistency with quality and patient safety.

- Coordination of resources of the participating processes; for example, performing tests prior to surgical procedures.

- Organization of personnel, formation of work teams and determination of premises, equipment, instruments and material for the performance of the processes.

- Times for the fulfillment of processes.

\section{The resident doctor}

Let us remember: "The residency is recognized as the best modality for postgraduate medical education"'. The hospital is the preferred place to carry out the residency, a setting of training in the acquisition of different clinical and surgical skills. In Mexico, according to the Federal Law of Labor, "Resident physician: medical professional with a legally issued title and registered before the competent authorities as being assigned to a resident-receiving medical unit to comply with a residency". In the aforementioned law, residency is stated to be: "The set of activities a resident doctor must comply with during the training period, in order to carry out postgraduate studies and practices regarding the health discipline he/she intends to work in, within a resident-receiving medical unit, during the time and in accordance with the requirements indicated by current academic regulations"2. According to the above, a medical residency is a training period in which the resident doctor is at the learning stage, performing clinical and surgical activities, where tacitly there are acts of management; most times, if not always, resident doctors lack knowledge thereof.

When residents -young doctors- arrive at a hospital or clinical area to start their activities, they arrive to a largely unknown environment and culture, and they are willing to learn, to excel themselves and to provide services. Sometimes they are guided with regard to their duties, they are offered a reception, an act of 
welcome with explanations about the institution, they are channeled into medical-administrative aspects; this happens in the best-case scenario, but in other occasions, they are immediately assigned a clinical-teaching activity, without the resident doctors knowing the departments, the processes or the type of patients. In any case, they perceive authorities and hierarchies, the need to comply with medical-administrative regulations and processes, and thus they must learn the values, rules and the different procedures of the institution.

According to that which was indicated in micromanagement, particularly with regard to medical-administrative processes, resident doctors should know their institution in terms of organization, personnel, hierarchies, physical resources, premises, property, clinical activities that are carried out, as well as the teaching and research activities. This favors their adaptation to services, as well as compliance with processes, which must be structured in order to achieve greater efficiency and effectiveness of human, technical, economic and administrative resources. Adequate development of processes contributes to generate the least inconveniences and costs for the user, the institutions, medical insurances and society. According to that which has been expressed, particularly as regards costs, it has been pointed out that "health professionals (essentially clinicians) allocate $70 \%$ of healthcare resources in their diagnostic and therapeutic decisions, made in conditions of uncertainty. Achieving proper clinical management is a task that entails coordinating resources and motivating people. Clinical management aims to restore patients' health levels, to the extent possible, through actions that concern individual patients or patient groups (grouped by a common condition or procedure, by care unit, etc.). Direct decisions about each patient are made by the doctor or nurse, working separately or as a team, and decisions that affect patient groups are mainly made by healthcare responsible entities. The fundamental discipline of clinical management is medicine"3.

The processes resident physicians participate in involve clinical, teaching and administrative activities practiced at all departments and areas within the hospital: outpatient services, hospitalization, emergency department, operating room, clinical tests laboratory, imaging, peritoneal dialysis, robotic surgery, etc.

Within the hospital setting, in reductionist terms, processes might be described as a set of activities developed between professionals and patients ${ }^{4}$. These processes must favor educational competences, foster creativity and innovation by resident doctors, and their knowledge is necessary, especially in problematic situations:

- Lack of assistance, supervision or advice from higher-ranked doctors, which forces residents to act on their own initiative in accordance with lex artis ad hoc; the resident doctor is responsible for his/her own acts. This aspect is highly important, particularly in view of the accelerated growth of defensive medicine, where more and more lawyers search where the error, failure or carelessness was in order to justify their client's argument looking for an economic settlement.

- Making decisions on their own that are not adequate to their educational level, not complying with indications or instructions ordered by higher ranked doctors or authorities.

The medical resident requires to be attentive to problematic situations, with an analytical and proactive mind, bearing in mind that on numerous occasions he/she must serve and work in areas that do not belong to his/her usual environment, work long hours or carry out unplanned, unforeseen activities, given the changing dynamics of the hospital. These are moments of doubt, of reflection, of uncertainty, of planning and making decisions; these are delicate situations not only for resident doctors, but also for patients and health care organizations. In these cases, resident doctors must demonstrate their capacity of management and application or creation of processes to align their experience, practices and skills with other areas' expectations. Along the way, they go discovering new paths, reinventing processes.

One issue that cannot be overlooked is residents' exhaustion and fatigue, since this affects the management and operation of processes, but, most importantly, it increases the risk in terms of patient safety in medical departments. Resident physicians often experience professional burnout syndrome, determined by the occupational stress they are subjected to, which is characterized by emotional fatigue, violent acts, depersonalization, low self-esteem, dissatisfaction or labor conflicts, demotivation and disinterest for activities. This syndrome can affect the quality of medical services and teaching ${ }^{5}$. This situation can be improved if resident doctors learn and apply micromanagement and processes. 


\section{PUEM and the Standard: health education for organization and operation of medical residencies}

Resident doctors on training, in their work and teaching activities, are regulated in Mexico by the Single Plan of Medical Specializations (PUEM - Plan Único de Especializaciones Médicas) and the Official Mexican Standard NOM-001-SSA3-2012 entitled Health Education for organization and operation of medical residencies. The PUEM is the code of regulations regarding student (residents) obligations and development in the specialization courses. It is a document prepared at the Faculty of Medicine of the National Autonomous University of Mexico, pointing out that its purpose is to train competent specialists in different fields of medical knowledge and activities, in order for them to be able to carry out a high-quality professional practice, integrating research and educational activities to their daily work in medical care. The PUEM contains general provisions, student obligations, student rights, faults incurred by students, sanctions, recognitions and incentives, and definitions, provisions and residents' activities are expressed $^{6}$.

In the Official Standard, section 4 contains definitions that are important for micromanagement and medical-administrative processes:

4.1. On-call duties: set of activities described and scheduled in the operative program, in addition to those that the resident doctor must carry out during the working day, at the resident-receiving medical unit he/she is appointed or assigned to.

4.2. Health institution: any public or private law organization with legal personality, with capacity to offer health services and respond for their order, structure and benefits in one or more medical care establishments.

4.3. Working day: number of hours during which, in workdays, the resident doctor must perform the functions and activities indicated in the medical residency operational program.

4.4. Resident physician: medical professional admitted to a resident-receiving medical unit to carry out a full-time medical residency.

4.5. Associate professor: specialist doctor assigned to the resident-receiving medical unit, who assists the full professor in planning, conducting and evaluating the corresponding medical residency.
4.6. Full professor: medical specialist assigned to the resident-receiving medical unit, appointed by the higher education institution, responsible for the planning, conduct and evaluation of the medical residency of the corresponding health institution.

4.7. Academic program: document issued by the higher education institution that contains the elements of the curriculum of the corresponding medical residency.

4.8. Operational program: document that describes the activities the resident physician must perform, in order to develop the academic program of the corresponding medical residency in resident-receiving medical units.

4.9. Medical residency: set of academic, healthcare-related and research activities that are to be accomplished by the resident doctor within the resident-receiving medical units, during the time stipulated in the corresponding academic and operational programs.

4.10. Field rotation: set of temporary activities contained in the operational program to be carried out by the resident doctor on the last year of the corresponding medical residency.

4.11. Teaching hospital: main resident-receiving medical unit, which complies with the infrastructure, equipment and teaching staff necessary for the resident doctor to develop all or most academic and operational programs of the corresponding medical residency.

4.12. National system of medical residences: group of health agencies and institutions responsible for the organization and operation of medical residencies for the training of medical specialists, through coordination with recognized higher education institutions and in accordance with the National Health System objectives and priorities.

4.13. Secondary site: resident-receiving medical unit, where the resident doctor can develop part of the academic and operational programs of the corresponding medical residency.

4.14. Competent administrative unit: general management responsible for conducting the national policy for the education, training and updating of human resources for health; for proposing, promoting and monitoring compliance with Mexican official standards regarding the education, training and updating of 
human resources for health; for regulating, controlling and evaluating the allocation of clinical fields and medical residency scholarships.

4.15. Resident-receiving medical unit: establishment for the provision of medical care services or areas or departments of the health institution that comply as academic settings, where resident doctors should carry out medical residencies.

4.16. Resident-receiving medical unit for field rotation: establishment for the provision of medical care services where the resident doctor must carry out his/her field rotation during the last year of medical residency, in accordance with the provisions of the competent administrative unit and as stipulated in the corresponding operative program.

The Official Standard indicates provisions regarding the full- and assistant professors that are necessary for management and medical-administrative processes. These provisions appear in section 9 and are the following:

9.1. Comply with the academic and professional requirements established by the higher education institution that recognizes medical residencies.

9.2. Meet the following requirements in order to be proposed by health institutions as full or assistant professor of a medical residency at resident-receiving medical units:

9.2.1. Being a medical specialist in the respective discipline and have a certificate authorizing the professional practice of the corresponding specialty.

9.2.2. Having a teaching experience of at least one year in the corresponding medical residency.

9.2.3. Being assigned to the resident-receiving medical unit and, where appropriate, carrying out healthcare activities inherent to the medical residence in question.

9.3. Carry out the following activities during the stay at the resident-receiving medical unit:

9.3.1. Coordinate and supervise resident physicians' healthcare-related, academic and research activities, indicated in the corresponding operative program.

9.3.2. Collaborate in the preparation of the operative program of the corresponding medical residency, following the guidelines of the health institution and the higher education institution where appropriate; considering the health needs of the population regarding the corresponding medical specialty and reinforcing the acquisition of useful skills for application of the acquired knowledge.

9.3.3. Evaluate the learning of resident physicians, in accordance with the corresponding academic and operational programs.

9.3.4. Supervise the development of academic and operational programs of the corresponding medical residency.

9.3.5. Evaluate the performance of teachers who participate with the resident in medical residency.

9.3.6. Inform, in writing, the resident doctors about their situation, whether he/she was promoted or not, in coordination with the corresponding higher education institution, in accordance with the rules and procedures established by the teaching head office of the resident-receiving medical units.

9.4. The director, deputy director, head of teaching or heads of department and their equivalents at the resident-receiving medical unit should not serve as full professors.

9.5. For medical residency optimal development, the full professor must have the collaboration of assistant professors, assistants, external guests, collaborators or others according to the existing nomenclature at the resident-receiving medical unit.

The informative appendix of the aforementioned Standard includes section 10 entitled Clinical and academic daily activities by department, which states: "It is the set of actions the resident physician must carry out at the department he/she is assigned to, including those related to teaching, where he/she should actively participate". The actions refer to visiting wards, reception and issuance of shift change reports, review and preparation of admissions, preparation of medical records, outpatient services, preparation of clinical notes, consultations, food intake, on-call duties, interpretation of studies, diagnostic and therapeutic procedures, discussion of diagnoses, review of clinical cases, conferences, bibliographic sessions, departmental sessions, general sessions, workshops, seminars and days of the week?. "These activities should be assigned on a schedule and separately for each academic 
degree." Compliance with these regulations involves management and processes. In other words, the referred Official Mexican Standard considers the essential elements for medical residencies, expressed in duties of the health institutions that are part of the National System of Medical Residences, pointing out that the Standard is intended to guarantee medical specialists optimal training, without undermining patient safety or population health care.

\section{The resident doctor and educational competences}

All the provisions on clinical and teaching activities presented in the PUEM and in the Standard "for organization and operation of medical residencies" involve management activities and medical-administrative processes that are required for medical residencies organization and operation in hospitals. In addition to the above-mentioned, the International Institute for Medical Education has indicated seven educational competencies that are necessary in medical care; all involve management and medical-administrative processes, and are the following:

1. Clinical skills.- Resident doctors should efficiently and effectively diagnose and provide treatment to patients.

2. Scientific medical foundations.- Resident physicians must have solid scientific knowledge, along with the ability to apply this knowledge to the solution of specific medical problems, and should understand the principles decisions and medical care are based on, and should adapt to the various changes and advances.

3. Professional values, attitudes, behavior and ethics.- Resident doctors must act with professionalism and ethical behavior, and should to keep in mind the principles of autonomy, beneficence, non-maleficence and justice.

4. Public health and health systems.- Resident doctors must possess knowledge in terms of health promotion, disease prevention, as well as of their practice; in addition, they should know the structure and heterogeneity of health departments, and their basic management.

5. Skills to analyze, value and criticize existing knowledge, technology and information, using the scientific method in research.

6. Management of information technology.- Resident doctors should understand the possibilities and limitations of information technology in the study of patients.

7.-Communication.- Resident doctors should have communication skills, understand and appreciate patients and their families, doctors, nurses and the general public ${ }^{8}$.

\section{Conclusion}

Resident physicians are the backbone of hospital clinical services, which is a reason that forces them to have knowledge on the specialty of their preference, as well as management skills, particularly in micromanagement and processes.

Management has an impact on resident doctor activities, essentially in three aspects: the first one is decision making, since resident doctors participate in the solution of problems, and by having knowledge on management they will make better medical-administrative decisions; the second aspect is the management of resources, which refers to the capacity and talent required for the proper conduction of a work team composed of human capital, the most valuable asset of the organization, rational use of material, physical, financial and technological resources; and the last aspect refers to medical-administrative processes, which should be governed by order and logic, thus facilitating the provision of services. That is, if the resident doctor becomes part of clinical management, this will contribute to the improvement of medical services, which will be provided with higher efficacy and efficiency. It should be noted that the purpose of clinical management by residents is to offer a quality service and safety for the patient and his/her family, always with ethics and humanism.

\section{Funding}

The authors declare no funding was necessary.

\section{Conflict of interests}

The authors declare there were no conflicts of interests.

\section{References}

1. Dal Bó A. Hospitales de reforma. Buenos Aires, Argentina: Editorial Biblos; 2008. p. 46.

2. Secretaría del Trabajo y Previsión Social. Ley Federal del Trabajo. México; 2012. p. 28. 
3. Lozano Kasten F. de J. Gestión hospitalaria. Macrogestión, mesogestión y microgestión. En: Martínez Ramírez A, coordinador. Gestión hospitalaria. Guadalajara, Jalisco, México: IDEA; 2007. p. 31.

4. Zanovello AL. Qualidade aplicada aos seviços de saude. En: Hoteleria hospital. Boeger MM. Coordinador. Barueri, São Paulo: Manole; 2011. p.75

5. Álvarez-Hernández G, Medécigo-Vite S, Ibarra-García C. Prevalencia del síndrome de desgaste profesional en médicos residentes de un hospital pediátrico en el Estado de Sonora. Boletín Médico del Hospital Infantil de México. 2010;67:15-23.
6. Plan Único de Especializaciones Médicas (PUEM). Facultad de Medicina, Universidad Nacional Autónoma de México. México;

7. Secretaría de Salud. Norma Oficial Mexicana NOM-001-SSA3-2012. Educación en salud para la organización y funcionamiento de residencias médicas. México; 2012. p. 5-12.

8. Institute for International Medical Education, Core Committee. Global minimum essential requirements in medical education. Medical Teacher 2002;24:130-5. Traducción al español en Educación Médica. 2003;6(Supl 2):11-9. 